\title{
Type 8 Adenylyl Cyclase Is Targeted to Excitatory Synapses and Required for Mossy Fiber Long-Term Potentiation
}

\author{
Hongbing Wang, ${ }^{1 \star}$ Victor V. Pineda, ${ }^{1 \star}$ Guy C. K. Chan, ${ }^{1}$ Scott T. Wong, ${ }^{1}$ Louis J. Muglia, ${ }^{2}$ and Daniel R. Storm ${ }^{1}$ \\ ${ }^{1}$ Department of Pharmacology, University of Washington, Seattle, Washington 98195-7280, and ${ }^{2}$ Departments of Pediatrics and Molecular Biology and \\ Pharmacology, Washington University School of Medicine, St. Louis, Missouri 63130
}

\begin{abstract}
Mossy fiber/CA3 long-term potentiation (LTP) is hypothesized to depend on cAMP signals generated by $\mathrm{Ca}^{2+}$-stimulated adenylyl cyclases $\mathrm{AC1}$ or AC8. AC1 gene knock-out mice $\left(\mathrm{ACl}^{-/-}\right)$show a partial reduction in mossy fiber LTP, suggesting that either AC8 activity is also critical for mossy fiber LTP or that there is a component of mossy fiber LTP that is independent of CaM-activated adenylyl cyclases. To address this issue, mossy fiber LTP was examined in hippocampal slices from $A C 8^{-1-}$ and $A C 1^{-/-} \times A C 8^{-1-}$ double knock-out mice (DKO). Despite the fact that AC8 contributes only a small fraction of the $\mathrm{Ca}^{2+}$-stimulated adenylyl cyclase activity in the hippocampus and is less sensitive to $\mathrm{Ca}^{2+}$ than $\mathrm{ACl}, A C 8^{-/-}$mice exhibited mossy fiber LTP defects comparable with $A C 1^{-/-}$and DKO mice. Furthermore, short-term plasticity was disrupted in $\mathrm{AC}^{-/-}$mice but not in $\mathrm{ACl}^{-/-}$mice. Because $\mathrm{ACl}$ is not localized at the excitatory synapses in hippocampal neurons, we hypothesized that AC8 may be targeted to synapses, in which higher synaptic-specific $\mathrm{Ca}^{2+}$ increases occur. Here, we report that AC8 accumulates in puncta of dendrites and axons in hippocampal neurons and colocalizes with synaptic marker proteins. These data indicate that both synaptic and nonsynaptic cAMP signals, generated by different $\mathrm{Ca}^{2+}$-stimulated adenylyl cyclases, are required for mossy fiber LTP.
\end{abstract}

Key words: adenylyl cyclase; axon; calcium; calmodulin; dendrite; hippocampus; LTP; MDCK; mossy fiber; paired-pulse facilitation; synapse; targeting

\section{Introduction}

Various forms of long-term potentiation (LTP) expressed in the hippocampus have a common requirement for increased intracellular $\mathrm{Ca}^{2+}$ initiated postsynaptically through NMDA receptors or presynaptically through voltage-sensitive $\mathrm{Ca}^{2+}$ channels (Kauer et al., 1988; Malenka et al., 1988; Nicoll et al., 1988). However, several forms of mechanistically distinct LTP have been described. For example, perforant path and Schaffer collateral/ CA1 LTP depend on activation of NMDA receptors (Bliss and Collingridge, 1993), whereas mossy fiber/CA3 LTP does not (Harris and Cotman, 1986; Zalutsky and Nicoll, 1990). Several forms of LTP in the hippocampus are associated with cAMP increases (Stanton and Sarvey, 1985a; Chetkovich et al., 1991; Chetkovich and Sweatt, 1993), which are required for LTP or enhance LTP (Wu et al., 1995; Villacres et al., 1998; Wong et al., 1999).

Because LTP is initiated by transient increases in intracellular $\mathrm{Ca}^{2+}$, the $\mathrm{Ca}^{2+}$-stimulated adenylyl cyclases are a potential

Received May 28, 2003; revised Aug. 27, 2003; accepted Sept. 3, 2003.

This research was supported by National Institutes of Health Grants NS 20498 (D.R.S.), AG18876 (L.J.M.), and AG 00057 (H.W.). V.V.P. was supported by United States Public Health Service National Research Service Award 1F31NS042475-01 from the National Institute of Neurological Disorders and Stroke. Wethank members of the Storm laboratory for reading and critical discussion of this manuscript.

*H.W. and V.V.P. contributed equally to this work.

Correspondence should be addressed to Dr. D. R. Storm, Department of Pharmacology, University of Washington, Seattle, WA 98195-7280. E-mail: dstorm@u.washington.edu.

S. T. Wong's present address: Division of Neurobiology, Department of Molecular and Cell Biology, University of California, Berkeley, CA 94720.

Copyright $\odot 2003$ Society for Neuroscience $\quad$ 0270-6474/03/239710-09\$15.00/0 source of cAMP signals required for LTP. Of the known adenylyl cyclases, only $\mathrm{AC} 1$ and $\mathrm{AC} 8$ are stimulated by $\mathrm{Ca}^{2+}$ and calmodulin (CaM) (for review, see Wang and Storm, 2003). AC1 is neurospecific (Xia et al., 1993) and expressed in the hippocampus, neocortex, entorhinal cortex, cerebellum, olfactory cortex, and pineal gland (Xia et al., 1991; Tzavara et al., 1996). AC8 is expressed in the hippocampus and cerebellum as well as in nonneuronal tissues, including lung and parotid gland (Cali et al., 1994; Watson et al., 1998; Muglia et al., 1999). Although AC1 and AC8 are both stimulated by $\mathrm{Ca}^{2+}$, half-maximal stimulation of $\mathrm{AC} 1$ is at $150 \mathrm{~nm}$ free $\mathrm{Ca}^{2+}$, whereas AC8 is approximately five times less sensitive to $\mathrm{Ca}^{2+}$ (Nielsen et al., 1996). The presence of AC1 and AC8 with different $\mathrm{Ca}^{2+}$ dependencies in the hippocampus may allow $\mathrm{Ca}^{2+}$ coupling to cAMP over a broader range of $\mathrm{Ca}^{2+}$ concentration than would be possible with only one of the enzymes. $\mathrm{ACl}$ is not stimulated by activation of $\mathrm{G}_{\mathrm{s}}-$ coupled receptors alone; however, it is stimulated by receptors when paired with $\mathrm{Ca}^{2+}$ increases (Wayman et al., 1994). Therefore, $\mathrm{AC} 1$ can function as a coincidence detector responding synergistically to $\mathrm{Ca}^{2+}$ and receptor activation in the hippocampus. AC8 is also stimulated by $\mathrm{Ca}^{2+} / \mathrm{CaM}$. However, it is not stimulated by $\mathrm{G}_{\mathrm{s}}$-coupled receptors alone, nor is it stimulated by $\mathrm{G}_{\mathrm{s}}$ coupled receptors when it is coactivated by $\mathrm{Ca}^{2+}$, indicating that AC8 is a pure $\mathrm{Ca}^{2+}$ sensor (Nielsen et al., 1996).

NMDA receptors are sparsely expressed in the mossy fibers of the hippocampus, and mossy fiber/CA3 LTP exhibits an NMDAindependent form of LTP (Nicoll and Malenka, 1995) that depends on protein kinase A (PKA) (Weisskopf et al., 1994). Be- 
cause mossy fiber LTP can be induced without postsynaptic activation (Castillo et al., 1994; Mellor and Nicoll, 2001), it was proposed that presynaptic $\mathrm{Ca}^{2+}$ increases activate $\mathrm{ACl}$ and causes a persistent enhancement of glutamate release (Weisskopf et al., 1994). This hypothesis is supported by the observation that the synaptic protein Rab3A, which is a PKA substrate, is required for mossy fiber LTP (Castillo et al., 1997; Lonart et al., 1998). It has also been suggested that CAMP-dependent modification of hyperpolarization-dependent cation channels $\left(I_{\mathrm{h}}\right)$ causes longterm depolarization of mossy fiber terminals (Mellor et al., 2002) (but see Chevaleyre and Castillo, 2002). However, postsynaptic mechanisms for mossy fiber LTP have also been suggested. For example, Yeckel et al. (1999) showed that mossy fiber LTP is also prevented by postsynaptic injection of a peptide inhibitor of cAMP-dependent protein kinase. A critical unanswered question is the source of cAMP signals required for mossy fiber LTP.

To test the hypothesis that $\mathrm{Ca}^{2+}$ activation of $\mathrm{AC} 1$ may be essential for mossy fiber LTP, the gene for AC1 was disrupted in mice. Wild-type (WT) and $A C 1^{-1-}$ mice exhibited comparable perforant path LTP and late-phase LTP (L-LTP) at the Schaffer collateral/CA1 synapse (Villacres et al., 1998; Wong et al., 1999). However, mossy fiber LTP was significantly impaired in $\mathrm{ACl}^{-/-}$ mice, although paired-pulse facilitation (PPF) was normal (Villacres et al., 1998). The residual LTP seen with AC1 mutant mice might be attributable to the presence of AC8, which is also expressed in the hippocampus. To resolve this issue, we examined mossy fiber LTP in $A C 8^{-/-}$and $A C 1^{-/-} \times A C 8^{-/-}$double knock-out (DKO) mice. Here we report that AC8 is targeted to excitatory synapses and is required for mossy fiber LTP, although it comprises a relatively minor fraction of total $\mathrm{Ca}^{2+}$-stimulated adenylyl cyclase activity in the hippocampus. The fact that mossy fiber LTP is dependent on both of the $\mathrm{Ca}^{2+}$-activated adenylyl cyclases is surprising and contrasts with L-LTP in area CA1, which is supported by either AC1 or AC8 but does not require both enzymes. This implies that different types of $\mathrm{Ca}^{2+}$ stimulated CAMP transients are required for mossy fiber and CA1 L-LTP. The fact that AC8, but not AC1, is concentrated at synapses in the hippocampus suggests the interesting possibility that mossy fiber LTP may require localized cAMP increases at several different intracellular sites.

\section{Materials and Methods}

Materials. Plasmids, pCDNA3-LacZ, pCDNA3-AC8, pCDNA3-HA$\mathrm{AC} 8$, and $\mathrm{pCI}_{\text {neo }}-\mathrm{HA}-\mathrm{AC} 1$ were used to express $\beta$-galactosidase, $\mathrm{AC} 8$, HA-AC8, and HA-AC1 in transfected cell lines and primary neuronal cultures. A hemagglutinin (HA) epitope, after a Kozak sequence and ATG start codon, were added to the $\mathrm{N}$ terminus of AC 8 and AC1 by PCR. The cDNA expression was driven by the cytomegalovirus promoter in all constructs. The native AC1 was cloned into $\mathrm{pCI}_{\text {neo, }}$, with 102 bp 5' untranslated region (UTR) and 471 bp 3'UTR. Kozak sequence, ATG, and HA tag were fused with the first 174 bp coding region by PCR and subcloned into $\mathrm{pCI}_{\text {neo }}-\mathrm{ACl}$ (by XhoI and SacII) to replace the corresponding sequence in the native $\mathrm{AC} 1$. The native $\mathrm{AC} 8 \mathrm{cDNA}$ was cloned into pCDNA3 with 776 bp 5'UTR and 77 bp 3'UTR. The PCR product containing Kozak sequence, ATG, HA tag, and the first 172 bp AC8 coding region was subcloned (by KpnI and Eco47 III) into pCNDA3AC8, so the 5'UTR was replaced. Polyclonal and monoclonal anti-HA antibodies were purchased from Clontech (Palo Alto, CA) and Convance, respectively. Monoclonal anti-MAP2 (microtubule-associated protein 2), monoclonal anti-calbindin, and monoclonal anti-PSD95 (postsynaptic density 95) antibodies were from Sigma (St. Louis, MO). Polyclonal anti-neurofilament (NF) 145, polyclonal anti-GAD (K2 antibody), monoclonal anti-synaptophysin, and polyclonal anti-synapsin I antibodies were from Chemicon (Temecula, CA). Polyclonal antivesicular GABA transporter (VGAT) was purchased from Biomol Re- search Laboratories (Plymouth Meeting, PA). Monoclonal anti- $\beta$ galactosidase was from Promega (Madison, WI). Horseradish peroxidase (HRP)-conjugated secondary antibodies were from Jackson ImmunoResearch (West Grove, PA). Fluorophore (Alexa Fluor 488 and 594)conjugated secondary antibodies were purchased from Molecular Probes (Eugene, OR). Tissue culture reagents were purchased from Invitrogen (Carlsbad, CA) and Sigma. All chemical reagents were from Sigma. $\left[\mathrm{H}^{3}\right]$ adenine was from ICN Biomedicals (Irvine, $\mathrm{CA}$ ).

Mutant mice. Mice lacking a functional $A C 8$ gene were generated by deletion of exon 1 and $2 \mathrm{~kb} 5^{\prime}$ flanking region through homologous recombination (Schaefer et al., 2000). Generation of AC1 mutant and $A C 1 \times A C 8$ DKO mice was described previously (Wu et al., 1995; Wong et al., 1999). Wild-type littermates were used as controls. The genotypes of the mutant mice were determined by PCR and Southern blot analysis. Brain samples from 8- to 12-week-old mice were used for anatomy analysis and electrophysiology.

cAMP accumulation assay. The relative changes in intracellular cAMP levels were measured by the cAMP accumulation assay (Wong et al., 1991) and determined by the ratio of cAMP to total ATP, ADP, and AMP pool. Primary cultured hippocampal neurons from wild-type, $A C 1^{-/-}$, and $A C 8^{-1-}$ mutant mice were incubated overnight with $3 \mu \mathrm{Ci}$ of $\left[{ }^{3} \mathrm{H}\right]$ adenine (ICN Biomedicals) on day in vitro 7 (DIV 7). Cells were washed twice with DMEM and pretreated for $30 \mathrm{~min}$ with $1 \mathrm{~mm}$ isobutylmethylxanthine (IBMX) to inhibit phosphodiesterase activity. After IBMX incubation, the cells were treated with $\mathrm{KCl}$ or forskolin for $10 \mathrm{~min}$. The incubation solution was replaced by $1 \mathrm{ml}$ of ice-cold $5 \%$ trichloroacetic acid containing $1 \mu \mathrm{M}$ cAMP to terminate the reaction. Acid soluble nucleotides were separated by Dowex AG-50 WX-4 and neutral alumina chromatography (Salomon et al., 1974).

Adenylyl cyclase activity assay. The CA3 region of the hippocampus was dissected from 2-month-old mutant and control wild-type mice. Membrane fractions from the CA3 homogenates were assayed for adenylyl cyclase activity as described previously (Wong et al., 1999).

Electrophysiology. After cervical dislocation, mouse brains were quickly removed and chilled in ice-cold oxygenated cutting buffer (in mm: $120 \mathrm{NaCl}, 3.5 \mathrm{KCl}, 1.3 \mathrm{MgCl}_{2}, 1.25 \mathrm{CaCl}_{2}, 1.25 \mathrm{NaH}_{2} \mathrm{PO}_{4}, 25.6$ $\mathrm{NaHCO}_{3}$, and 10 glucose). Four hundred micrometer transverse hippocampus slices were prepared using a vibratome. The slices were transferred to an interface-recording chamber and allowed to recover at $34^{\circ} \mathrm{C}$ for $1 \mathrm{hr}$ before recording. Artificial CSF (ACSF) (similar to the cutting buffer but with $2.5 \mathrm{mM} \mathrm{CaCl}_{2}$ ) was used during electrophysiology experiments with temperature maintained at $34^{\circ} \mathrm{C}$. For mossy fiber/CA3 recording, $50 \mu \mathrm{M} \mathrm{D}$-2-amino-5-phosphonovaleric acid (APV) was supplemented to block NMDA receptors. A concentric bipolar stimulating electrode (100 $\mu \mathrm{m}$ in diameter; Rhodes Medical Supply) was placed near granule cell bodies in stratum granulosum of the upper blade of the dentate gyrus to stimulate mossy fiber responses or in the middle third of the molecular layer of the dentate gyrus to stimulate the medial perforant path (MPP). High-resistance microelectrodes (1-2 $\mu \mathrm{m}$ tips) filled with 3 $\mathrm{M} \mathrm{NaCl}$ were used for recording. The recording electrode was placed in the stratum lucidum of CA3 (for mossy fiber response). Dendritic field EPSP (fEPSP) responses of the MPP were recorded from the middle third of the molecular layer. For perforant path/dentate gyrus (DG) LTP, ACSF with $50 \mu \mathrm{m}$ bicuculline was used, and the recording electrode was placed in the granule cell layer for population spike. Baseline activity was established by stimulation at $0.016 \mathrm{~Hz}$ for at least $30 \mathrm{~min}$. The stimulation intensity that evoked $50 \%$ of the maximal response was chosen, and traces were digitized by Digidata 1200 (Axon Instruments, Foster City, CA). The data were collected and analyzed by Axoscope 1.1 (Axon Instrument). Mossy fiber/CA3 LTP was induced by four $1 \mathrm{sec}$ trains at 100 $\mathrm{Hz}$ with $20 \mathrm{sec}$ intervals, and perforant path/dentate gyrus LTP was induced by three $1 \mathrm{sec}$ trains at $100 \mathrm{~Hz}$ with $20 \mathrm{sec}$ intervals.

Analysis of hippocampal morphology. Freshly dissected brains were cut into $500 \mu \mathrm{m}$ slices, fixed in PBS with 6\% paraformaldehyde and $50 \mathrm{~mm}$ HEPES, pH 7.6, for $6 \mathrm{hr}$, and subsequently cryoprotected with 30\% sucrose-PBS for $24 \mathrm{hr}$. Histological analysis was performed by Neutral Red staining using $40 \mu \mathrm{m}$ coronal sections. Immunocytochemistry detection using calbindin antibody (1:1000) was performed to stain mossy fibers. Antibodies against synapsin I (1:500), VGAT (1:1000), and MAP2 (1: 
500) were used to compare general synapse formation and neuron numbers between wild-type and mutant mice. FITC- and rhodamine redconjugated secondary antibodies were used (1:500) for fluorescent detection.

Cell culturing and transfection. Human embryonic kidney 293 (HEK293) and Madin-Darby canine kidney (MDCK) cells were cultured in DMEM and 10\% FBS supplemented with $1 \%$ penicillin and streptomycin at $37^{\circ} \mathrm{C}, 5 \% \mathrm{CO}_{2}$. Brain regions from postnatal day 1 mice or rats were used for cortical or hippocampal primary cultures. After dissection, cortices or hippocampi were digested with $10 \mathrm{U} / \mathrm{ml}$ papain (Worthington, Freehold, NJ) in dissociation buffer $\left(82 \mathrm{mM} \mathrm{Na}_{2} \mathrm{SO}_{4}, 30 \mathrm{mM} \mathrm{K}_{2} \mathrm{SO}_{4}\right.$, $5.8 \mathrm{~mm} \mathrm{MgCl}_{2}, 0.25 \mathrm{~mm} \mathrm{CaCl}_{2}, 20 \mathrm{~mm}$ glucose, $0.001 \%$ phenol red, and $1.5 \mathrm{~mm}$ HEPES, $\mathrm{pH} 7.6$ ) at $37^{\circ} \mathrm{C}$ for $30-45 \mathrm{~min}$. The digestion was washed and triturated with Neurobasal medium (Invitrogen). The cells were seeded on coverslips (Bellco Glass, Vineland, NJ) coated with 100 $\mu \mathrm{g} / \mathrm{ml}$ poly-D-lysine (Sigma) and $6.7 \mu \mathrm{g} / \mathrm{ml}$ laminin (Invitrogen). One hour after plating, Neurobasal was replaced with growth media. The cells were grown in Neurobasal, 1\% FBS, $1 \times$ B27 supplement (Invitrogen), $1 \times$ penicillin-streptomycin, and $0.5 \mathrm{~mm}$ glutamine. Twenty-four hours after initial plating, the medium was changed, and $5 \mu \mathrm{M}$ AraC was added to inhibit the growth of non-neuronal cells. One-third of the medium was replenished every $3 \mathrm{~d}$ during the culturing of neurons.

Plasmids, pCDNA3-LacZ, pCDNA3-AC8, and pCDNA3-HA-AC8 were transfected into HEK293 or MDCK cell lines using a lipid-based method. The growth media were replaced by DMEM without serum. Plasmids were mixed with Lipofectamine 2000 (Invitrogen) according to the instructions of the manufacturer. The cells were incubated with Lipofectamine 2000-DNA mix for $4 \mathrm{hr}$ and replaced by growth media. For primary cultured neurons, a DNA-Lipofectamine mix was made in growth medium without serum and antibiotics. The incubation time for transfection was $2 \mathrm{hr}$. The conditioned medium was then added to replace the transfection solution.

Western analysis. Transfected HEK293 cells were lysed with SDSPAGE loading buffer. The lysates were then separated by $7.5 \%$ SDSPAGE and transferred to Immobilon membranes (Millipore, Bedford, MA). The membranes were blocked with $3 \%$ nonfat milk in PBS- $0.1 \%$ Triton X-100 (PBST) for $1 \mathrm{hr}$ and then incubated with monoclonal anti-HA (1:1000) or polyclonal anti-HA (1:1000) for $1 \mathrm{hr}$ at room temperature. The membranes were then washed with PBST and incubated with HRP-conjugated secondary antibodies (1:5000) for $1 \mathrm{hr}$ at room temperature. Western blots were visualized by the ECL (Amersham Biosciences, Arlington Heights, IL) method.

Immunofluorescence cytochemistry. Forty-eight hours after transfection, the subcellular localization of HA-tagged AC8 in HEK293 cells, MDCK cells, or primary neuronal cultures were analyzed by immunofluorescent staining. The cells were washed with PBS and fixed with $4 \%$ paraformaldehyde for $15 \mathrm{~min}$ at room temperature. The cells were then permeabilized by 30 min incubation with $0.1 \%$ Triton X-100 and PBS. In some preparations, the cells were fixed and permeabilized at the same time by treatment with cold methanol for $10 \mathrm{~min}$. PBST containing 3\% serum and $3 \%$ BSA was used as blocking solution. Monoclonal anti-HA (1:350) or polyclonal anti-HA (1:100) was used to detect HA-AC8. Monoclonal anti MAP2 (1:500) was used for staining cell body and dendrites. Polyclonal anti-NF145 (1:500) was used to label axons. Synapses were labeled by antibodies against synaptic marker proteins synaptophy$\sin (1: 40)$ or synapsin I (1:500). Excitatory glutamate synapses were stained by a monoclonal anti-PSD95, and the inhibitory synapses were blocked by polyclonal anti-GAD (1:500) or polyclonal anti-VGAT (1: 1000). The fluorophore (Alexa Fluor 488 and 594)-conjugated secondary antibodies (1:200; Molecular Probes) were used for fluorescence detection. The samples were mounted by water-based mounting medium (Gel/Mount; Biomeda, Foster City, CA) and examined by Leica (Nussloch, Germany) confocal system using TCSNT software.

\section{Results}

$\mathrm{AC} 1$ is the major $\mathrm{Ca}^{2+}$-activated adenylyl cyclase in the CA3 region of hippocampus

Hippocampal membrane preparations from DKO mice showed no detectable $\mathrm{Ca}^{2+}$-stimulated adenylyl cyclase activity, indicat-
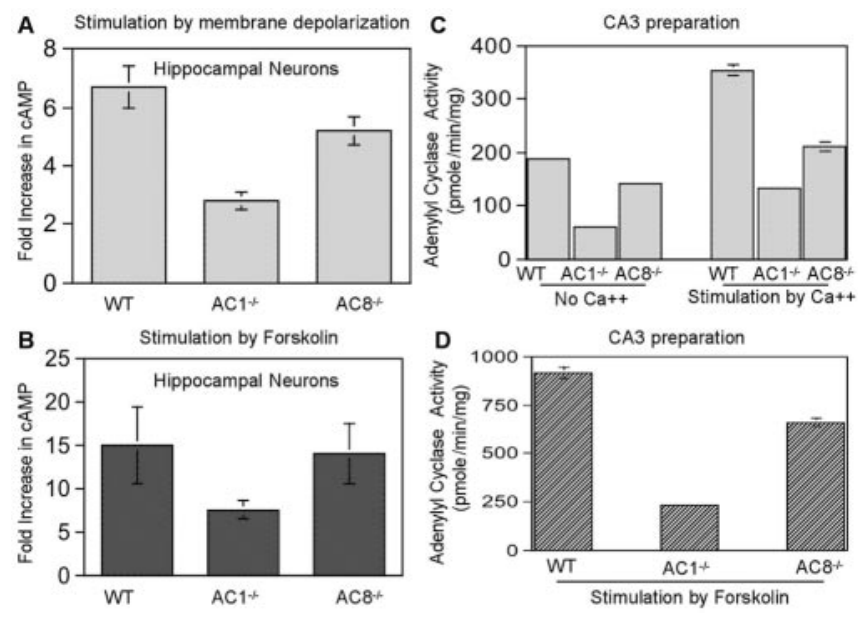

Figure 1. $A, B, A C 1$ is the major $\mathrm{Ca}^{2+}$-activated adenylyl cyclase in hippocampal neurons. Hippocampal neurons from postnatal day 1 wild-type, $A C 1^{-/-}$, and $A C 8^{-/-}$mice were cultured as described in Materials and Methods. Day 7 cultures were assayed for $\mathrm{Ca}^{2+}$-stimulated and forskolin-stimulated adenylyl cyclase activity as described in Material and Methods. A, Treatment with $50 \mathrm{~mm} \mathrm{KCl}$. B, Treatment with $25 \mu \mathrm{m}$ forskolin. C, D, AC1 contributed more AC activity in the $\mathrm{CA} 3$ region of hippocampus. The $\mathrm{CA} 3$ region was dissected from 2-month-old $A C 1^{-I-}, A C 8^{-1-}$, and WT mice. The membrane fraction was used for AC activity measurement. Basal and $\mathrm{Ca}^{2+}$-stimulated activity was shown in C. Forskolin-stimulated activity was shown in $D$. The data are presented as mean \pm SEM for triplicate determinations.

ing that AC1 and AC8 are the only CaM-stimulated adenylyl cyclases in the hippocampus (Wong et al., 1999). The expression pattern of AC1 and AC8 within hippocampus was examined by in situ studies. The highest AC1 mRNA level was found in the DG (Xia et al., 1991). The mRNA of AC8 level was uniform throughout the entire hippocampus (Cali et al., 1994). However, Muglia et al. (1999) reported recently that AC8 mRNA is high in CA1 and low in DG (Muglia et al., 1999). An analysis of CaM-stimulated adenylyl cyclase in hippocampal membranes from $\mathrm{AC1}^{-/-}$and $A C 8^{-/-}$mice indicated that most of the $\mathrm{Ca}^{2+}$-stimulated adenylyl cyclase in membrane preparations is attributable to $\mathrm{AC} 1$, with a smaller contribution from AC8. When cultured hippocampal neurons from $\mathrm{AC}^{-1-}$ mice were analyzed for $\mathrm{Ca}^{2+}$-stimulated cAMP accumulation, there was an $\sim 20 \%$ decrease in $\mathrm{Ca}^{2+}$ activated adenylyl cyclase compared with wild-type mice (Fig. $1 A$ ) and little or no decrease in forskolin-stimulated adenylyl cyclase (Fig. $1 B$ ). Within the CA3 region, the decrease in $\mathrm{Ca}^{2+}$ stimulated adenylyl cyclase activity was $\sim 61.3 \%$ for $A C 1^{-/-}$and $37 \%$ for $A C 8^{-\prime-}$ mice (Fig. 1C). Furthermore, forskolinstimulated adenylyl cyclase activity was lower in $A C 1^{-/-}$mice than $A C 8^{-/-}$mice (Fig. $1 D$ ). Collectively, these data indicated that $\mathrm{AC} 1$ is the major $\mathrm{Ca}^{2+}$-stimulated adenylyl cyclase in the $\mathrm{CA} 3$ region of the hippocampus.

\section{$A C 8^{-/-}$mice exhibit impaired paired-pulse facilitation and mossy fiber LTP}

Mossy fiber LTP was monitored in the presence of APV to block NMDA receptors. Mossy fiber responses in hippocampal slices from wild-type mice were characterized by a large PPF (Fig. $2 B$ ) and a rapid rise in fEPSP $(<3 \mathrm{msec})$. The $A C 8^{-/-}$mice had an input-output curve similar to wild-type mice, suggesting that basal synaptic transmission was intact in AC8 mutant (Fig. 2A). Although the trend-line values for WT $\left(y=1.09 x ; R^{2}=0.658\right)$, AC8 $\left(y=0.9929 x ; R^{2}=0.8081\right)$, and DKO $\left(y=1.0255 x ; R^{2}=\right.$ 0.6941 ) were different (Fig. $2 A$ ), they were not statistically significant $(p>0.2)$. Although AC8 comprises $<20 \%$ of the $\mathrm{Ca}^{2+}$ - 
A
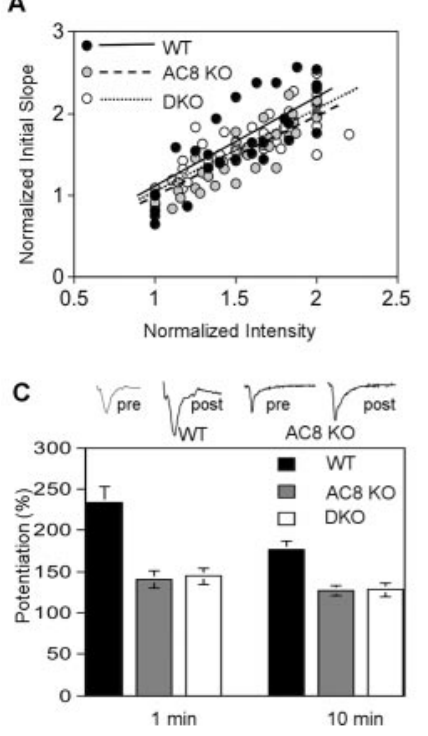
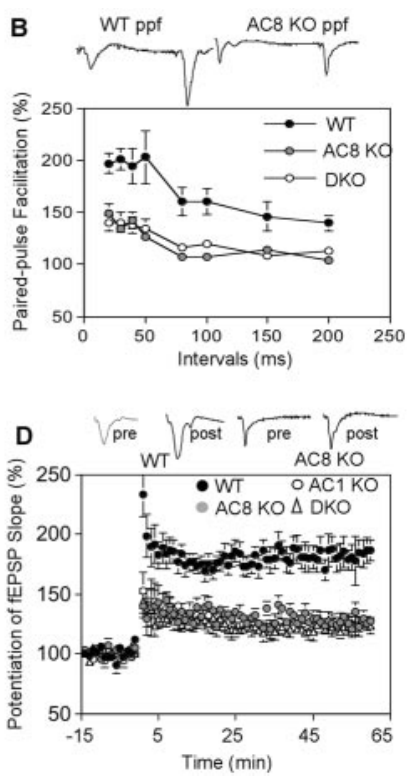

Figure 2. $A C 8^{-/-}$and DKO mice show impaired paired-pulse facilitation, PTP, and mossy fiber LTP. A, Normal basal neural transmission in mutant mice. The input- output curves were determined by 30 data points from WT, 37 from AC8 mutant, and 50 from DKO mice. Each value was an average of two measurements. Data and trend lines for each genotype are indicated. $B$, Paired-pulse facilitation was measured by applying two stimuli with different intervals. The ratio of slope of the second fEPSP to the first is presented as percentage of facilitation. Data are mean \pm SEM from 10 wild-type, $10 \mathrm{AC}^{-/-}$, and 10 DKO mice. PPF with 40 msec interval was displayed in the representative traces. $C$, Comparison of PTP of wild-type $(n=13), A C 8^{-/-}$ $(n=9)$, and DKO $(n=8)$ mice. The PTP values at 1 and 10 min after high-frequency stimulation are reported. D, Mossy fiber LTP was induced by four trains of stimulation at $100 \mathrm{~Hz}$, separated by $20 \mathrm{sec}$. APV was perfused to block NMDA receptors. Data are presented as mean $\pm S E M$ for 13 wild-type, seven $A C 1^{-/-}$, nine $A C 8^{-/-}$, and eight DKO mice. The values are mean \pm SEM. Sample traces are shown for wild-type and $A C 8^{-/-}$mice. The percentage change in fEPSP slope is used to express LTP and PTP values. The symbols for different genotypes were indicated.

stimulated adenylyl cyclase activity in the hippocampus, hippocampal slices from $A C 8^{-/-}$mice had little or no mossy fiber LTP (Fig. 2C,D). Short-term plasticity, including post-tetanic potentiation (PTP) and PPF, was also seriously impaired in $A C 8^{-/-}$mice (Fig. $2 B, C$ ). $A C 8^{-/-}$and DKO mice showed similar short-term defects in PTP and PPF (Fig. $2 B, C$ ). The mossy fiber LTP defect with $A C 8^{-/-}$mice was comparable with that seen when genes for both of the $\mathrm{Ca}^{2+}$-stimulated adenylyl cyclases were ablated. Although mossy fiber LTP was significantly reduced in $A C 8^{-1-}$ mice and DKO mice, there was residual LTP that does not require $\mathrm{AC} 1$ or AC8. These data, taken with previously published results (Villacres et al., 1998), indicate that AC1 and AC8 both contribute to mossy fiber LTP.

\section{$A C 1^{-/-}, A C 8^{-/-}$, and DKO mice have normal} hippocampal morphology

To determine whether $A C 1^{-/-}, A C 8^{-/-}$, or DKO mice have defects in hippocampal structure, we performed a detailed morphological analysis of the mutant mice (Fig. 3). We were unable to detect any obvious structural changes in the hippocampus of the mutant mice (Fig. 3A). For example, the mossy fiber formation, visualized by calbindin staining, was comparable between the wild-type and mutant mouse strains (Fig. 3B). Furthermore, staining with MAP2, synapsin I, and VGAT antibodies indicated that the neuron density and synapse density in the CA3 region of the hippocampus of $A C 1^{-/-}, A C 8^{-/-}$, and DKO mice were normal (Fig. $3 C-E)$. These mutant mice also showed normal staining

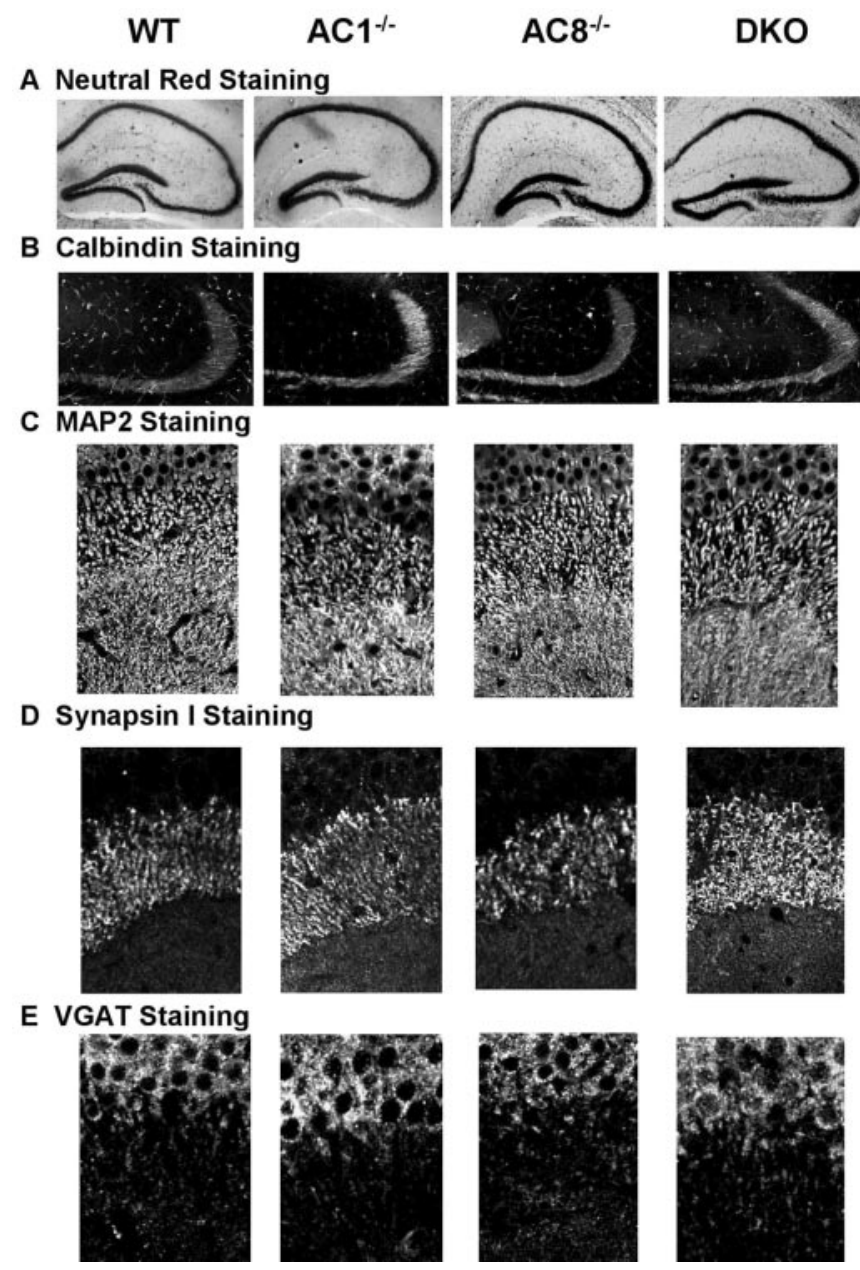

Figure 3. Adenylyl cyclase mutant mice exhibit normal hippocampal morphology and synapse density. $A$, Neutral Red staining of cell bodies in hippocampus showed normal morphology. $B$, Mossy fiber formation stained by calbindin antibodies was comparable between wildtype, $A C 1^{-/}, A C 8^{-/-}$, and DKO mice. C, MAP2 staining of cell bodies and dendrites showed no differences between wild-type, $A C 1^{-1-}, A C 8^{-/-}$, and DKO mice in CA3 region. D, Synapses were stained with an antibody against the synaptic protein synapsin I. The mutant and wildtype mice had similar synapse density in CA3. E, The density of inhibitory synapses in CA3, measured by staining for VGAT, was normal in adenylyl cyclase mutant mice.

for MAP2, synapsin I, and VGAT in the CA1 and DG regions (data not shown).

\section{Hippocampal slices from $A C 8^{-/-}$mice exhibit normal perforant path LTP}

Perforant path LTP, from pyramidal cells in the entorhinal area to the granule cells of the dentate gyrus, is induced by $\beta$-adrenergic agonists (Harley, 1991) and blocked by $\beta$-adrenergic antagonists (Bramham et al., 1997). Forskolin enhances norepinephrine-induced perforant path LTP, and highfrequency stimulation of the perforant path increases cAMP (Stanton and Sarvey, 1985b). Collectively, these observations suggest that $\beta$-adrenergic receptor-mediated cAMP increases may be required for perforant path LTP. Because $A C 1^{-/-}$mice exhibit normal perforant path LTP (Villacres et al., 1998), we examined perforant path LTP in hippocampal slices from $A C 8^{-1-}$ mice (Fig. 4). The input-output values between WT and AC8 mutant mice were not statistically different $(p=0.21)$, although their trend lines were not overlapping ( $y=1.0158 x$, $R^{2}=0.8035$ for WT; $y=1.1065 x, R^{2}=0.6836$ for $A C 8$ mutant) 

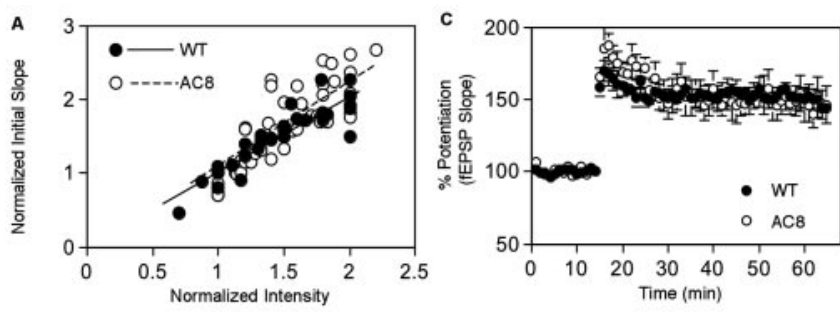

B
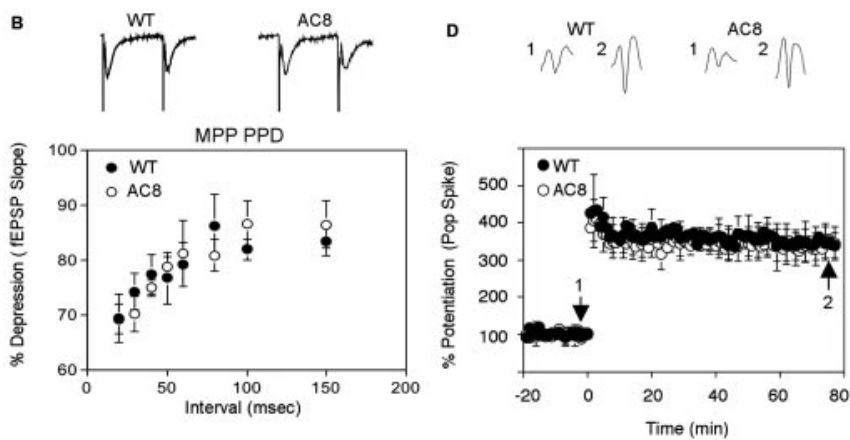

Figure 4. $A C 8^{-1-}$ mice exhibit normal perforant path LTP. A, Normal basal neural transmission in mutant mice. The input- output curves were determined by 30 data points from WT and 48 from $A C 8$ mutant mice. Each value was an average of two measurements. Data and trend lines for each genotype were indicated. $B$, PPD in MPP was normal in $A C 8^{-1-}$ mice. PPD was measured in MPP at different intervals ( $n=8$ forWT; $n=6$ for $A 8^{-1-}$ ). Representative traces (with 40 msec interval) were displaced for WT and $A C 8^{-1-}$ mice. The slopes of fEPSPs in the MPPs were compared to determine the degree of depression. C, D, Perforant path LTP was generated using three trains of $100 \mathrm{~Hz}$ stimulation, separated by $20 \mathrm{sec}$. The train duration was $1 \mathrm{sec}$. Data were collected at $0.0167 \mathrm{~Hz}$. LTP were measured by fEPSP in MPP from eight WT and nine $A C 8$ mutant ( $C$ mice, as well as by population spike from $15 A C 8^{-/-}$and 17 wild-type $(D)$ mice. Representative traces before (trace 1) and after (trace 2) tetanic stimulation are displayed. The data are presented as mean $\pm \mathrm{SEM}$.

(Fig. 4A). This suggested that the basal neural transmission is normal in AC8 mutant mice. Paired-pulse depression (PPD) in the medial perforant path of $A C 8^{-/-}$mice was similar to wildtype mice at all of the intervals tested, indicating that the shortterm plasticity were normal in the mutant (Fig. $4 B$ ). We examined both field EPSP (Fig. 4C) and population spikes (Fig. 4D) for perforant LTP in the DG region. In contrast to mossy fiber LTP, $A C 8^{-/-}$mice exhibited perforant path LTP that was indistinguishable from wild-type mice (Fig. $4 C, D$ ). These data indicate that CaM-stimulated adenylyl cyclase activity is dispensable for perforant path LTP.

HA-tagged AC8 is catalytically active

Because AC8 is only a small fraction of total $\mathrm{Ca}^{2+}$-stimulated adenylyl cyclase activity in hippocampal neurons, it was surprising that mossy fiber LTP was seriously compromised in $A C 8^{-/-}$ mice. However, the unexpected dependency of mossy fiber LTP on AC8 may reflect its subcellular location. Because appropriate antibodies for rodent AC8 are not available, we attached an HA epitope at the $\mathrm{N}$ terminus of AC8 to trace the subcellular targeting of the enzyme. We expressed HA-AC8 in HEK293 cells and assayed for adenylyl cyclase activity to ensure that the HA tag did not interfere with the structure and enzymatic activity of AC8. $\mathrm{Ca}^{2+}$ stimulation of adenylyl cyclase activities in cells transfected with AC8 or HA-tagged AC8 were comparable (Fig. 5A). HAtagged AC8 also showed similar forskolin sensitivity as AC8 (Fig. $5 B$ ). Comparable results were obtained when HA-tagged AC1 was expressed in HEK293 cells (Wang et al., 2002).

To examine whether the HA-tagged AC8 can be detected using anti-HA antibodies, we analyzed transfected HEK293 cells for

\section{A $\mathrm{Ca}^{++}$Stimulated Adenylate Cyclase Activity}

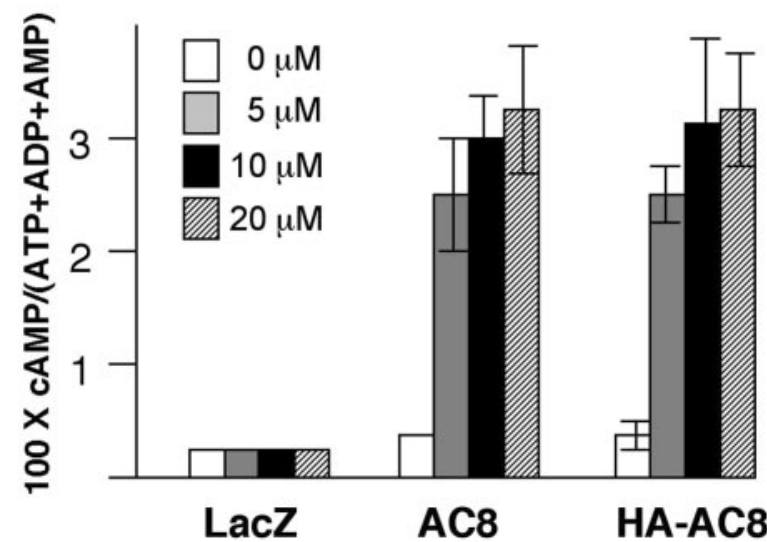

\section{B Forskolin Stimulated Adenylate Cyclase Activity}

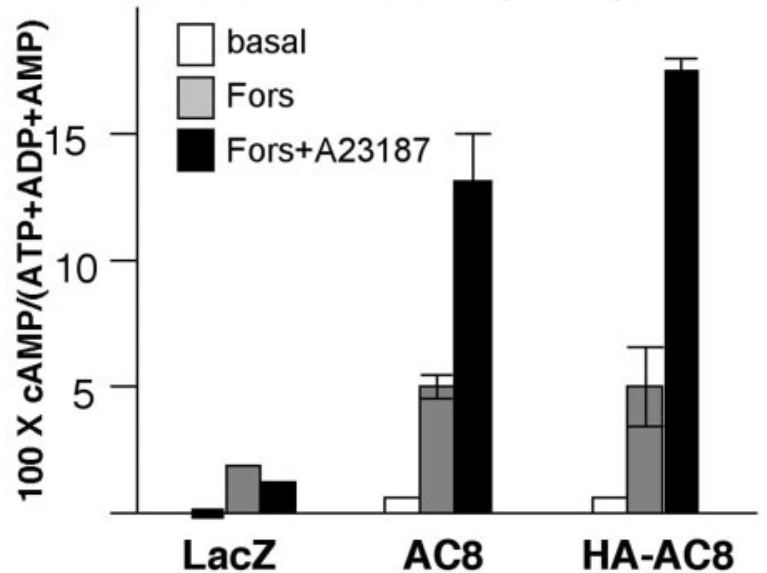

C

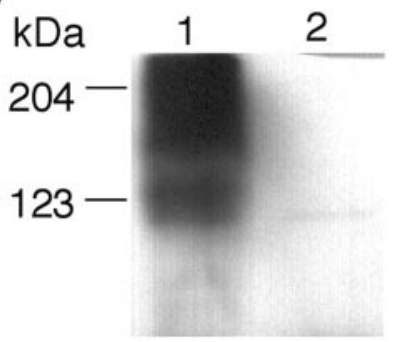

D

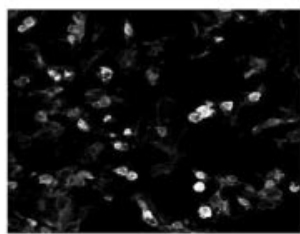

Figure 5. HA-tagged AC8 is catalytically active and stimulated by $\mathrm{Ca}^{2+}$. $\mathrm{LaC} \mathrm{Z}, \mathrm{AC} 8$, and HA-AC8 expression plasmids were transfected to HEK293 cells as described in Materials and Methods. Adenylyl cyclase activity was assayed $48 \mathrm{hr}$ after transfection as described in Materials and Methods. A, Adenylyl cyclase activity in the presence of $\mathrm{Ca}^{2+}$. The transfected cells were treated with 5, 10, or $20 \mathrm{Ca}^{2+}$ ionophore A23187. The data are reported as mean \pm SD for triplicates. $B$, Effect of forskolin and combination of forskolin and $\mathrm{Ca}^{2+}$ on adenylyl cyclase activity. When present, forskolin was at $5 \mu \mathrm{m}$ and $\mathrm{A} 23187$ was at $10 \mu \mathrm{m}$. The data are reported as mean \pm SD for triplicates. C, HA-AC8 expressed in HEK293 cells was detected by monoclonal anti-HA antibodies as two diffuse bands on Western blots. The first lane was loaded with lysates from HA-AC8 transfected HEK293 cells and lane 2 with lysates from LacZ transfected cells. D, HA-AC8 expression in HEK293 cells was detectable by immunofluorescent staining using a monoclonal anti-HA antibody.

HA-AC8 expression by Western blot (Fig. 5C) and immunofluorescent cytochemistry (Fig. 5D). The lysates from HA-ACexpressing cells showed two bands on Western blots, one with a molecular mass of $\sim 123 \mathrm{kDa}$, corresponding to the calculated molecular weight and another at a higher molecular weight, presumably the glycosylated form of the enzyme. The expression of HA-AC8 was also detected by immunofluorescent staining of 


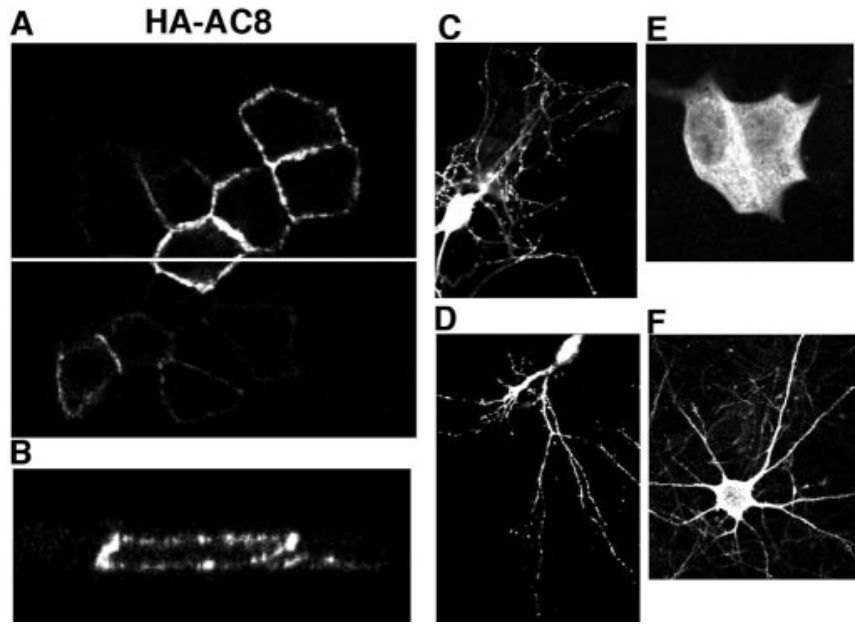

Figure 6. Intracellular targeting of HA-AC8 in MDCK cells and primary neuronal cultures. Forty-eight hours after transfection, MDCK cells were analyzed by immunofluorescent cytochemistry, as described in Materials and Methods. $A, x-y$ plane scan for immunoactivity in HA-AC8 transfected cells. The white line in $A$ was chosen as the $y$-axis for an $x-z$ scan. $B$, Apical and basolateral targeting of $\mathrm{HA}-\mathrm{AC} 8$ in MDCK cells. Punctate staining of HA-AC8 was observed for MDCK cells, as well as neurons (at DIV 9) from cortex ( $C$ and hippocampus (D). $\beta$-Galactosidase showed diffuse cytosolic staining when expressed in MDCK cells $(E)$ and hippocampal neurons $(F)$.

HEK293 cells (Fig. 5D). The staining was specific, and no signal was detected with non-tagged adenylyl cyclases or LacZ transfected cells (data not shown).

\section{Expression of HA-AC8 in MDCK cells}

The canine epithelial MDCK cell line has been used extensively as a model system to study protein targeting and localization. Apical expression in MDCK cells usually correlates with axonal localization in neurons, whereas basolateral expression correlates with dendritic localization (Matter and Mellman, 1994). We transfected MDCK cells with cDNAs encoding HA-AC8 and examined its localization by immunocytochemistry. HA-AC8 was mainly targeted to the cell membrane and absent from the nucleus (Fig. 6). The control protein LacZ was detected in cytoplasm (Fig. 6E). When the cells were scanned through the $x-z$ plane, we observed both apical and basolateral expression of HA-AC8, suggesting that AC8 may be targeted to both axons and dendrites of neurons (Fig. 6A, $B$ ).

\section{AC8 targets to dendrites and axons of cultured hippocampal neurons}

HA-AC8 was expressed in cultured hippocampal neurons to determine whether the enzyme colocalizes with dendritic (MAP2) or axonal (NF145) markers (Fig. 7). Staining with an anti-HA antibody indicated that AC8 is expressed in the cell body of cortical and hippocampal neurons with a punctate distribution in neurites (Fig. 6C,D), whereas LacZ showed diffuse distribution (Fig. 6 F). The expression pattern of HA-AC8 in neurons was not affected when the amount of DNA used for transfections was varied from 0.4 to $2 \mu \mathrm{g}$ of DNA per well (data not shown). On DIV 5, neurite formation of cultured neurons becomes more elaborate, and neurons are considered mature (Dotti et al., 1988); however, synapses are not fully developed at this stage. Therefore, we examined HA-AC8 expression patterns at different stages (on DIV 3, 5, 7, 9, and 12) and found that the intracellular targeting of HA-AC8 was similar except that the neurons had more elaborate neurite networks at later stages. Some of the AC8 colocalized with
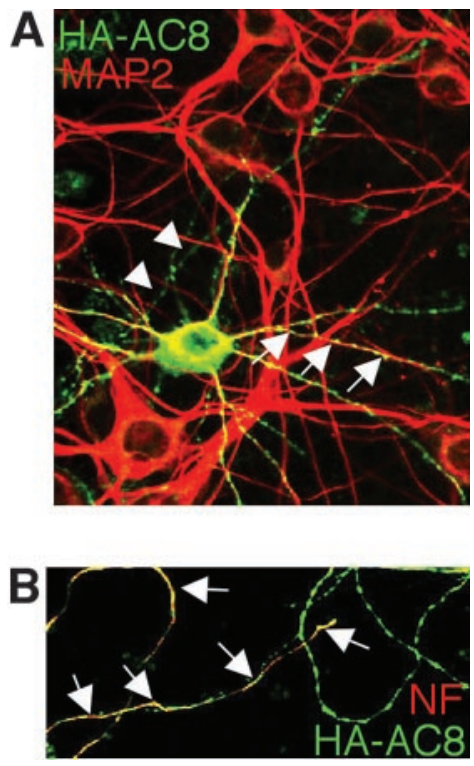

Figure 7. Dendritic and axonal targeting of AC8 in hippocampal neurons. Hippocampal neurons were transfected with an $\mathrm{HA}-\mathrm{AC} 8$ expression plasmid and analyzed by immunocytochemistry $48 \mathrm{hr}$ later. The neurons were double stained with polyclonal anti-HA and monoclonal anti-MAP2 antibodies $(A)$ or with monoclonal anti-HA and polyclonal anti-NF145 ( $B)$. A, HAAC8 colocalized with MAP2, a dendritic marker. B, HA-AC8 colocalized with NF145, an axonal marker. Arrows indicate colocalization.

MAP2 (Fig. 7A) or NF145 (Fig. 7B). This indicates that AC8 is targeted to dendrites and axons of hippocampal neurons, consistent with the distribution of AC8 in MDCK cells.

\section{Targeting of AC8 to excitatory synapses}

To determine whether HA-AC8 is specifically targeted to synapses, cortical and hippocampal neurons expressing HA-AC8 were stained with an anti-HA antibody and antibodies against synaptophysin or synapsin I, markers for synapses (Fig. 8). As early as DIV 5, synapses can be visualized in cultured neurons by synaptophysin immunocytochemistry. Compared with neurons at DIV 5, cultured neurons on DIV 9 exhibited more intense staining for synaptophysin, indicating that the synapses are more fully developed at this stage. HA-AC8 in neurites colocalized with synapsin I as well as synaptophysin, indicating that it targets to synapses (Fig. 8). Furthermore, HA-AC8 colocalized with PSD95, a marker for glutamate synapses (Fig. 9A, B), but not with GAD (Fig. 9C) or VGAT (Fig. 9D), markers for inhibitory synapses. This indicates that AC8 accumulates at excitatory but not inhibitory synapses. In contrast to AC8, HA-AC1 did not colocalize with markers for either excitatory or inhibitory synapses in hippocampal neurons (Fig. 10). AC1 is targeted to sites that are $\sim 1-2 \mu \mathrm{m}$ away from excitatory synapses.

\section{Discussion}

Mossy fiber LTP depends on a cAMP signal generated from one or more of the seven adenylyl cyclases expressed in the hippocampus (Weisskopf et al., 1994). Studies with $A C 1^{-/-}$mice indicated that $\mathrm{Ca}^{2+}$-stimulated adenylyl cyclase activity is required for full expression of mossy fiber LTP (Villacres et al., 1998). Nevertheless, the ablation of the $A C 1$ gene did not completely eliminate mossy fiber LTP, leaving open the possibility that other adenylyl cyclases may also contribute. The objective of this paper was to evaluate the role of AC8 for mossy fiber LTP using $A C 8^{-/-}$mice.

An examination of adenylyl cyclase activity in hippocampal 
neurons indicated that AC8 accounts for $<20 \%$ of the total $\mathrm{Ca}^{2+}$-stimulated adenylyl cyclase in the hippocampus. Surprisingly, mossy fiber LTP was seriously compromised in hippocampal slices from $A C 8^{-/-}$mice. Mice lacking both $\mathrm{ACl}$ and AC8 still expressed low-level mossy fiber LTP, suggesting that there may be a minor component of mossy fiber LTP that is independent of CaM-stimulated adenylyl cyclase activity. These data, and our previous report showing that $\mathrm{AC} 1$ is required for full expression of mossy fiber LTP (Villacres et al., 1998), indicate that both of the CaM-stimulated adenylyl cyclases contribute to mossy fiber LTP.

Although our data support the hypothesis that $\mathrm{Ca}^{2+}$ stimulation of adenylyl cyclases may be a major signaling component of mossy fiber LTP (Weisskopf et al., 1994; Villacres et al., 1998), it does not differentiate between a requirement for presynaptic or postsynaptic cAMP increases. AC1 and AC8 expressed in cultured hippocampal neurons both colocalize with presynaptic/axonal and postsynaptic/dendritic makers. Expression studies in MDCK cells also suggest that the two enzymes may be expressed presynaptically and postsynaptically in neurons. The fact that CaM-stimulated adenylyl cyclase activity is required for postsynaptic (Wong et al., 1999) and presynaptic (Villacres et al., 1998) LTP indicates that CaMstimulated adenylyl cyclases are expressed both presynaptically and postsynaptically. It seems likely that mossy fiber LTP depends on presynaptic, $\mathrm{Ca}^{2+}$-stimualted cAMP increases; however, postsynaptic cAMP increases may also contribute. For example, the probability of mossy fiber LTP induction is increased with postsynaptic injection of the cAMP analog 8-bromo-cAMP (Hopkins and Johnston, 1988).

Although several forms of LTP in the brain depend on CaM-stimulated adenylyl cyclases, their dependencies on AC1 and AC8 differ markedly. Transcriptiondependent L-LTP in area CA1 of the hippocampus is not decreased in hippocampal slices from $A C 1^{-/-}$or $A C 8^{-/-}$mice but is completely lost in DKO mice. Either $\mathrm{AC} 1$ or AC8 can provide the CAMP signal required for L-LTP (Wong et al., 1999). LTP at the parallel fiber/Purkinje cell synapse is completely ablated in $A C 1^{-/-}$mice (Storm et al., 1998), which probably reflects the concentration of AC1 at these excitatory synapses (Wang et al., 2002). In contrast, we show that mossy fiber LTP depends on both AC1 and AC8.

There are several possible reasons why AC1 and AC8 are both

B
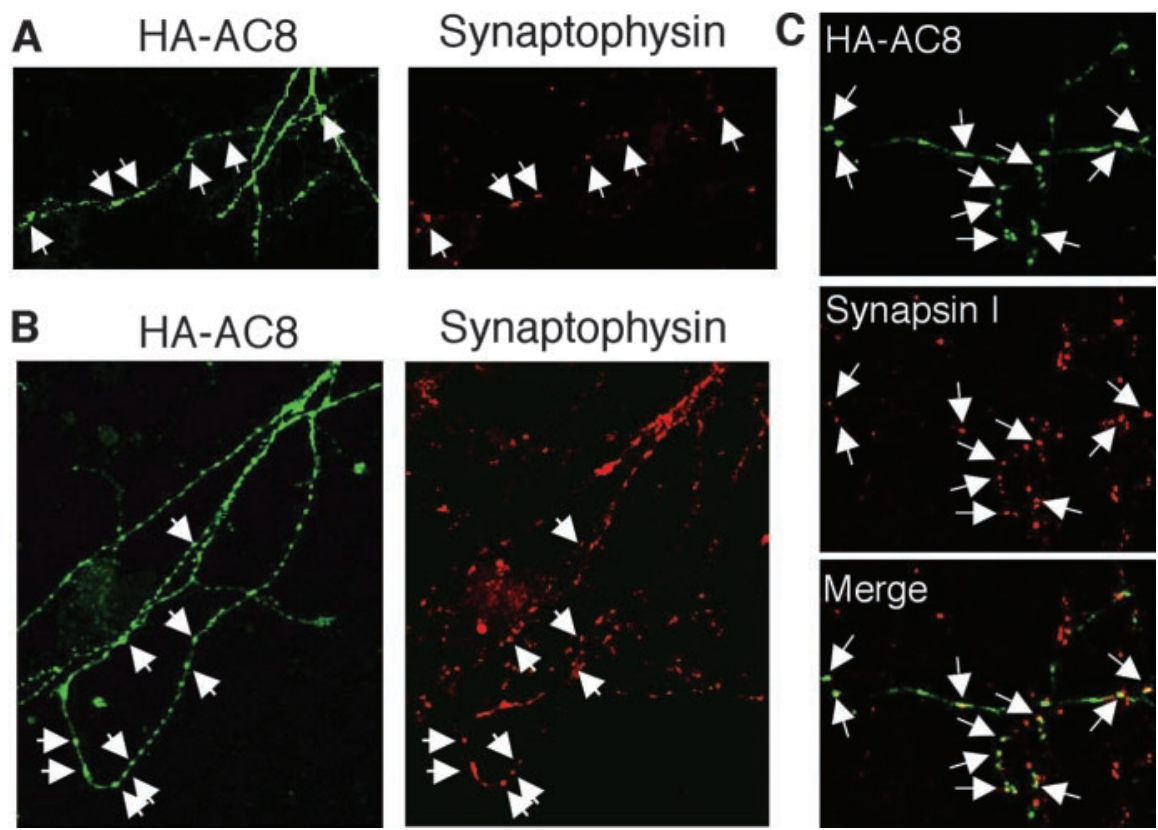

Figure 8. Targeting of $A C 8$ to synapses in cultured neurons. A, HA-AC8 transfected cortical neurons were stained with polyclonal anti-HA (green) and monoclonal anti-synaptophysin (red) on DIV 5. B, Colocalization of AC8 and synaptophysin in hippocampal neurons on DIV 9.C, Colocalization of AC8 with synapsin I in hippocampal neurons on DIV 9. Only the neurites of neurons are shown for better visualization. The colocalization of AC8 with synaptophysin or synapsin I is indicated by arrows.
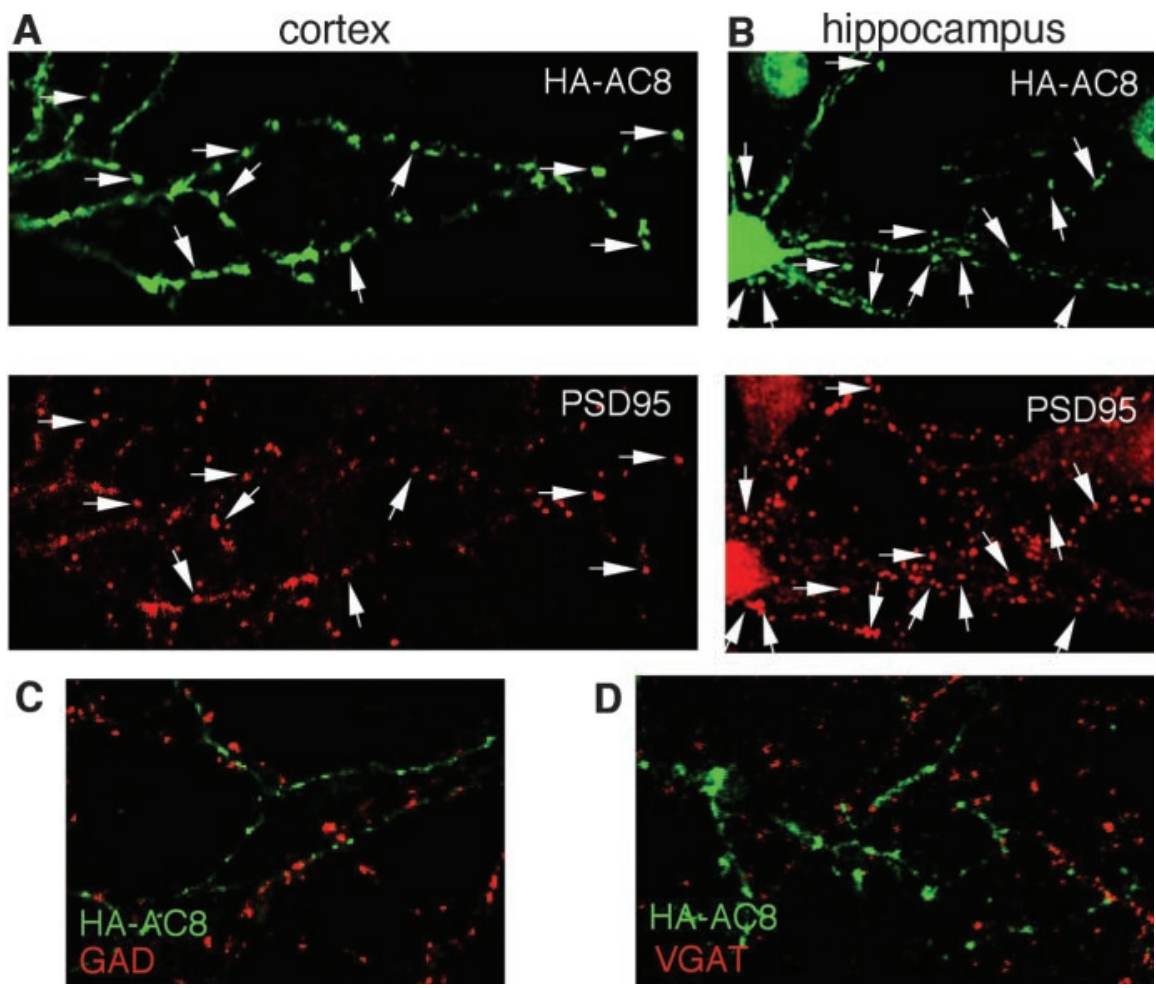

Figure 9. Targeting of AC8 to glutamate but not inhibitory synapses. Cortical $(A)$ or hippocampal $(B)$ neurons were transfected with CDNA encoding HA-AC8 and analyzed on DIV 10. Transfected neurons were double stained with polyclonal anti-HA (green) and monoclonal anti-PSD95 (red) antibodies. The colocalization of AC8 with PSD95 is indicated by arrows. Similarly, the transfected hippocampal neurons (on DIV 10) were double stained by anti-HA (green) and GAD (red; C) or VGAT (red; D). No colocalization was observed for HA-AC8 and these inhibitory synaptic markers.

required for mossy fiber LTP. Our data indicate that AC8 is localized to excitatory synapses, whereas AC1 is $\sim 1-2 \mu \mathrm{m}$ distant from excitatory synapses. This suggests the interesting possibility 

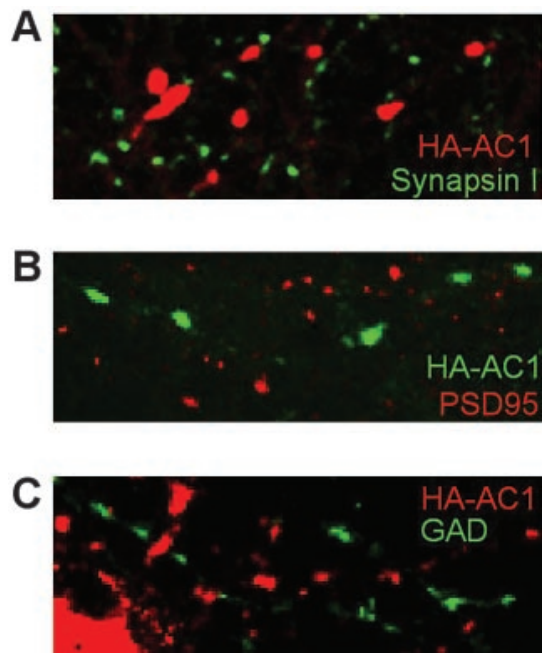

Figure 10. AC1 is not targeted to synapses of hippocampal neurons. HA-AC1 expression plasmid was transfected into hippocampal neuron on DIV 7 and analyzed on DIV 9. A, HA-AC1 showed a punctate expression pattern but did not colocalize with synapsin I. B, HA-AC1 did not colocalize with PSD95. C, HA-AC1 did not colocalize with GAD. HA-AC1 was stained with monoclonal anti-HA ( $A, C$; red) and polyclonal anti-HA ( $B$; green).

that mossy fiber LTP may depend on cAMP increases at the synapse and at sites distal to the synapse. Although AC8 is much less sensitive to $\mathrm{Ca}^{2+}$ than $\mathrm{AC1}$, its concentration at excitatory synapses ensures that it will be maximally stimulated by synaptic activity. Furthermore, the presence of two $\mathrm{Ca}^{2+}$ activated adenylyl cyclases with different $\mathrm{Ca}^{2+}$ sensitivities, at or near excitatory synapses, broadens the $\mathrm{Ca}^{2+}$ concentration range over which cAMP can be increased. Another distinguishing feature between $\mathrm{AC} 1$ and $\mathrm{AC} 8$ is that $\mathrm{AC} 1$ is stimulated through $\beta$-adrenergic receptors when it is activated by $\mathrm{Ca}^{2+}$. In contrast, AC8 is not activated through $\beta$-adrenergic receptors, even in the presence of $\mathrm{Ca}^{2+}$ signaling. Interestingly, the CA3 region receives extensive noradrenergic innervation, and mossy fiber LTP is potentiated by activation of $\beta$-adrenergic receptors (Hopkins and Johnston, 1988; Huang and Kandel, 1996). This effect of $\beta$-adrenergic agonists on mossy fiber LTP may be mediated by AC1.

In conclusion, mossy fiber LTP depends on the activity of two CaM-activated adenylyl cyclases with different regulatory properties. The fact that mossy fiber LTP requires $\mathrm{Ca}^{2+}$ stimulation of cAMP at the synapse as well as at sites distal to the synapse indicates a level of signaling complexity not previously appreciated. Mossy fiber LTP apparently depends on $\mathrm{Ca}^{2+}$-stimulated cAMP increases that are provided by the discrete localization and unique regulatory properties of the $\mathrm{Ca}^{2+}$-stimulated adenylyl cyclases.

\section{References}

Bliss TVP, Collingridge GL (1993) A synaptic model of memory: long-term potentiation in the hippocampus. Nature 361:31-39.

Bramham CR, BacherSvendsen K, Sarvey JM (1997) LTP in the lateral perforant path is beta-adrenergic receptor-dependent. NeuroReport 8:719-724.

Cali JJ, Zwaagstra C, Mons N, Cooper DMF, Krupinski J (1994) Type VIII adenylyl cyclase: $\mathrm{C} \mathrm{Ca}^{2+} /$ calmodulin stimulated enzyme expressed in discrete regions of rat brain. J Biol Chem 269:12190-12196.

Castillo PE, Weisskopf MG, Nicoll RA (1994) The role of $\mathrm{Ca}^{2+}$ channels in hippocampal mossy fiber synaptic transmission and long-term potentiation. Neuron 12:261-269.

Castillo PE, Janz R, Sudhof TC, Tzounopoulos T, Malenka RC, Nicoll RA (1997) Rab3A is essential for mossy fibre long-term potentiation in the hippocampus. Nature 388:590-593.
Chetkovich DM, Sweatt JD (1993) NMDA receptor activation increases cAMP in area $\mathrm{CA} 1$ of the hippocampus via $\mathrm{Ca}^{2+} /$ calmodulin stimulation of adenylyl cyclase. J Neurochem 61:1933-1942.

Chetkovich DM, Gray R, Sweatt JDD (1991) N-methyl-D-aspartate receptor activation increases cAMP levels and voltage gated $\mathrm{Ca}^{2+}$ channel activity in area CA1 of hippocampus. Proc Natl Acad Sci USA 88:6467-6471.

Chevaleyre V, Castillo PE (2002) Assessing the role of Ih channels in synaptic transmission and mossy fiber LTP. Proc Natl Acad Sci USA 99:9538-9543.

Dotti CG, Sullivan CA, Banker GA (1988) The establishment of polarity by hippocampal neurons in culture. J Neurosci 8:1454-1468.

Harley C (1991) Noradrenergic and locus coeruleus modulation of the perforant path-evoked potential in rat dentate gyrus supports a role for the locus coeruleus in attentional and memorial processes. Prog Brain Res 88:307-321.

Harris EW, Cotman CW (1986) Long-term potentiation of guinea pig mossy fiber responses is not blocked by $N$-methyl D-aspartate antagonists. Neurosci Lett 70:132-137.

Hopkins WF, Johnston D (1988) Noradrenergic enhancement of long-term potentiation at mossy fiber synapses in the hippocampus. J Neurophysiol 59:667-687.

Huang YY, Kandel R (1996) Modulation of both the early and the late phase of mossy fiber LTP by the activation of $\beta$-adrenergic receptors. Neuron 16:611-617.

Kauer JA, Malenka RC, Nicoll RA (1988) NMDA application potentiates synaptic transmission in the hippocampus. Nature 334:250-252.

Lonart G, Janz R, Johnson KM, Sudhof TC (1998) Mechanism of action of rab3A in mossy fiber LTP. Neuron 21:1141-1150.

Malenka RC, Kauer JA, Zucker RS, Nicoll RA (1988) Postsynaptic calcium is sufficient for potentiation of hippocampal synaptic transmission. Science 242:81-84.

Matter K, Mellman I (1994) Mechanisms of cell polarity: sorting and transport in epithelial cells. Curr Opin Cell Biol 6:545-554.

Mellor J, Nicoll RA (2001) Hippocampal mossy fiber LTP is independent of postsynaptic calcium. Nat Neurosci 4:125-126.

Mellor J, Nicoll RA, Schmitz D (2002) Mediation of hippocampal mossy fiber long-term potentiation by presynaptic Ih channels. Science 295:143-147.

Muglia LM, Schaefer ML, Vogt SK, Gurtner G, Imamura A, Muglia LJ (1999) The $5^{\prime}$-flanking region of the mouse adenylyl cyclase type VIII gene imparts tissue-specific expression in transgenic mice. J Neurosci 19:2051-2058.

Nicoll RA, Malenka RC (1995) Contrasting properties of two forms of longterm potentiation in the hippocampus. Nature 377:115-118.

Nicoll RA, Kauer JA, Malenka RC (1988) The current excitement in longterm potentiation. Neuron 1:97-103.

Nielsen MD, Chan GCK, Poser SW, Storm DR (1996) Differential regulation of type I and type VIII Calcium-stimulated adenylyl cyclases by G(i)coupled receptors in vivo. J Biol Chem 271:33308-33316.

Salomon Y, Londos D, Rodbell M (1974) A highly sensitive adenylate cyclase assay. Anal Biochem 58:541-548.

Schaefer ML, Wong ST, Wozniak DF, Muglia LM, Liauw JA, Zhuo M, Nardi A, Hartman RE, Vogt SK, Luedke CE, Storm DR, Muglia LJ (2000) Altered stress-induced anxiety in AC8 deficient mice. J Neurosci 20:4809-4820.

Stanton PK, Sarvey JM (1985a) The effect of high-frequency electrical stimulation and norepinephrine on cyclic AMP levels in normal versus norepinephrine-depleted rat hippocampal slices. Brain Res 358:343-348.

Stanton PK, Sarvey JM (1985b) Blockade of norepinephrine-induced longlasting potentiation in the hippocampal dentate gyrus by an inhibitor of protein synthesis. Brain Res 361:276-283.

Storm DR, Hansel C, Hacker B, Parent A, Linden DJ (1998) Impaired cerebellar long-term potentiation in type I adenylyl cyclase mutant mice. Neuron 20:1199-1210.

Tzavara ET, Pouille Y, Defer N, Hanoune J (1996) Diurnal variation of the adenylyl cyclase type 1 in the rat pineal gland. Proc Natl Acad Sci USA 93:11208-11212.

Villacres EC, Wong ST, Chavkin C, Storm DR (1998) Type I adenylyl cyclase mutant mice have impaired mossy fiber long-term potentiation. J Neurosci 18:3186-3194.

Wang H, Storm DR (2003) Calmodulin-regulated adenylyl cyclases: cross- 
talk and plasticity in the central nervous system. Mol Pharmacol 63:463-468.

Wang H, Chan GC, Athos J, Storm DR (2002) Synaptic concentration of type-I adenylyl cyclase in cerebellar neurons. J Neurochem 83:946-954.

Watson EL, Wu ZL, Jacobson KL, Storm DR, Singh JC, Ott SM (1998) Capacitative $\mathrm{Ca}^{2+}$ entry is involved in cAMP synthesis in mouse parotid acini. Am J Physiol 43:C557-C565.

Wayman GA, Impey S, Wu Z, Kindsvogel W, Prichard L, Storm DR (1994) Synergistic activation of the type I adenylyl cyclase by $\mathrm{Ca}^{2+}$ and Gscoupled receptors in vivo. J Biol Chem 269:25400-25405.

Weisskopf MG, Castillo PE, Zalutsky RA, Nicoll RA (1994) Mediation of hippocampal mossy fiber long-term potentiation by cyclic AMP. Science 265:1878-1882.

Wong ST, Athos J, Figueroa XA, Pineda VV, Schaefer ML, Chavkin CC, Muglia LJ, Storm DR (1999) Calcium-stimulated adenylyl cyclase activity is critical for hippocampus dependent long-term memory and latephase LTP. Neuron 23:787-798.
Wong YH, Federman A, Pace AM, Zachary I, Evans T, Pouyssegur J, Bourne HR (1991) Mutant alpha subunits of Gi2 inhibit cyclic AMP accumulation. Nature 351:63-65.

Wu ZL, Thomas SA, Villacres EC, Xia Z, Simmons ML, Chavkin C, Palmiter RD, Storm DR (1995) Altered behavior and long-term potentiation in type I adenylyl cyclase mutant mice. Proc Natl Acad Sci USA 92:220-224.

Xia Z, Choi EJ, Wang F, Blazynski C, Storm DR (1993) Type I calmodulinsensitive adenylyl cyclase is neural specific. J Neurochem 60:305-311.

Xia ZG, Refsdal CD, Merchant KM, Dorsa DM, Storm DR (1991) Distribution of mRNA for the calmodulin-sensitive adenylate cyclase in rat brain: expression in areas associated with learning and memory. Neuron 6:431-443.

Yeckel MF, Kapur A, Johnston D (1999) Multiple forms of LTP in hippocampal CA3 neurons use a common postsynaptic mechanism. Nat Neurosci 2:625-633.

Zalutsky RA, Nicoll RA (1990) Comparison of two forms of long-term potentiation in single hippocampal neurons. Science 248:1619-1624. 